\title{
BMJ Global Health Action to protect the independence and integrity of global health research
}

To cite: Storeng KT, Abimbola S Balabanova D, et al. Action to protect the independence and integrity of global health research. BMJ Global Health 2019;4:e001746. doi:10.1136/ bmjgh-2019-001746

Received 30 May 2019 Accepted 30 May 2019

Check for updates

(c) Author(s) (or their employer(s)) 2019. Re-use permitted under CC BY-NC. No commercial re-use. See rights and permissions. Published by BMJ.

${ }^{1}$ Centre for Development and the Environment, University of Oslo, Oslo, Norway

${ }^{2}$ Department of Infectious Disease Epidemiology, London School of Hygiene \& Tropical Medicine, London, UK ${ }^{3}$ School of Public Health, University of Sydney, Sydney, New South Wales, Australia ${ }^{4}$ Department of Global Health and Development, London School of Hygiene \& Tropical Medicine, London, UK ${ }^{5}$ Centre for Primary Care and Public Health, Queen Mary University London, London, UK ${ }^{6}$ Institute for Research on Sustainable Development (IRD), CEPED (IRD-Université deParis), Université de Paris, ERL INSERM SAGESUD, Paris, France ${ }^{7}$ Department of Mental Health, Faculty of Medicine, Gulu University, Gulu, Uganda

Correspondence to Katerini T Storeng; katerini.storeng@sum.uio.no

\author{
Katerini T Storeng, ${ }^{01,2}$ Seye Abimbola, ${ }^{3}$ Dina Balabanova, ${ }^{4}$ David McCoy, \\ Valery Ridde, ${ }^{\circ}$ Veronique Filippi, ${ }^{2}$ Sidsel Roalkvam, ${ }^{1}$ Grace Akello, ${ }^{7}$ \\ Melissa Parker, ${ }^{4}$ Jennifer Palmer, ${ }^{4}$ on behalf of the signatories
}

\section{INTRODUCTION}

In a recent Viewpoint in the Lancet, some of us shared our experience of censorship in donor-funded evaluation research and warned about a potential trend in which donors and their implementing partners use ethical and methodological arguments to undermine research. ${ }^{1}$

Reactions to the Viewpoint-and lively debate at the 2018 Global Symposium on Health Systems Research-suggest that similar experiences are common in implementation and policy research commissioned by international donors to study and evaluate large-scale, donor-funded health interventions and programmes, which are primarily implemented in low resource settings. 'We all have the same stories', was one of the first comments on the Viewpoint, followed by many private messages divulging instances of personal and institutional pressure, intimidation and censorship following attempts to disseminate unwanted findings. Such pressure comes from major donors and from international non-governmental organisations (NGOs) obliged to have an external assessment but who then maintain a high degree of confidentiality and control.

That such experiences are widespread reflects the deeply political nature of the field of 'global health' and the interconnections between priority setting, policy making and project implementation, which sit within a broader set of deeply entrenched power structures. ${ }^{23}$ Researchers in this field routinely find themselves working withinand studying-complex power relations and so experience challenges in negotiating their own position between interests of commissioning agencies and funders, implementers and country governments, as well as those of their own research institutions and their partnerships with other researchers spanning high-income, middle-income and low-income countries. ${ }^{4-7}$ They often receive research funding from major donor agencies like the UK Department of International Development (DFID), the US Agency for International Development (USAID), the Agence Française de Développement (AFD), UNITAID and the Bill and Melinda Gates Foundation, ${ }^{8}$ who commission evaluations for their own funded projects, even though they have a stake in results that demonstrate the success of a multibillion-dollar investment.

Effects of interference in the research and evaluation process are compounded by more subtle acts of self-censorship and data embellishment that can arise as researchers become embroiled in what was recently called the global health 'success cartel'. ${ }^{9}$ Their involvement in a collective drive to demonstrate success can unintentionally "instil a fear of failure, stifle risk-taking and innovation, and lead to the fabrication of achievement'. ${ }^{9}$ For example, research that threatens the position of powerful elites-such as research into high-level corruption-is lacking. ${ }^{10}$ Meanwhile, selective reporting of 'unwelcome' findings can be a way to avoid contractual terminations even though it undermines learning. ${ }^{1112}$ Moreover, perverse incentives exist across the global health and development sectors to use simplistic indicators of success and bad or fudged data. ${ }^{13-15}$ Donor agencies exacerbate the problem by distorting research findings to exaggerate their own successes. ${ }^{16-19}$

Researchers are responsible for conducting research ethically and with integrity. Yet, without strong and reliable institutional support, they are often in a vulnerable position when faced with vested interests. What action is needed to avoid undermining independent and critical research findings? What kind of institutional structures and practices might support researchers in dealing with the ethical and political dilemmas associated with 
the dissemination of (potentially) contested research findings and evaluation results?

To start a discussion on ways forward, we invited input from an international network of global health, health systems and policy researchers from diverse disciplines. Below, we discuss suggestions, endorsed by more than 200 researchers based in 40 different countries (see the full list of signatories below), on how the organisations that commission, undertake and publish research and evaluations can safeguard independence and integrity.

\section{COMMISSIONING BODIES}

In the first instance, those commissioning external research must enable conditions for independence. Commissioning agencies should be transparent about the purpose and principles of external evaluation and research to their implementing partners and should commit to upholding the principles of good research: ethical, methodologically sound and responsive to population needs. They should specify in the grant contract to researchers that they can review and provide input but will not interfere in the design, data collection, analysis or dissemination of any findings and that they fully commit to making all findings publicly available, whatever their content, including through academic (peer-reviewed) publication. Contractual clauses that limit the dissemination of potentially critical findings-such as DFID's new standard terms and conditions for service contracts (including evaluations), which prevent researchers from embarrassing DFID or bringing it into disrepute ${ }^{20}-$ should be deleted, since these terms jeopardise the independence of evaluation and research.

For each study, an independent research oversight committee should be established. The committee should include a broad range of stakeholders to avoid institutional bias and linkages with key funders, as well as fairly selected representatives from the communities that are being studied or civil society organisations who can assess the potential benefits and risks generated by the research. A key mandate of oversight committees would be to identify potential conflicts of interests and develop guidelines on rules of engagement between the commissioners and researchers. Such committees should be in a position to intervene or arbitrate if conflict arises, such as if the commissioner or implementing partners pressure, harass or threaten researchers, or if implementing partners feel that the researchers have misrepresented, traduced or misunderstood their work.

To prevent undue influence, donor agencies who commission research and evaluations should develop strong accountability measures between their operational departments and their research and evaluation departments. For example, it is well known in clinical medicine that pharmaceutical industry-funded trials are more likely to produce positive, flattering results than are independently funded trials. ${ }^{21-25}$ It is time to debate this important issue in global health too and to ask the question as to whether donor agencies should issue tenders for, commission and oversee evaluation and research involving their own programmes or whether it would be better for an arm's length body to do so. To increase transparency and reduce selective reporting of findings, we recommend establishing a global health evaluation registry, similar to existing clinical trial registries. $^{12} 26$

\section{RESEARCHERS AND RESEARCH INSTITUTIONS}

Today, universities and research organisations across the world depend heavily on external funding from government departments, private foundations and industry. ${ }^{2}$. Therefore, they have an important responsibility to prevent conflicts of interest in research contracts. While better core funding would strengthen research institutions' power over their own research priorities, they must also seek new ways to protect themselves from interference from external funders. Senior leadership in academia has a responsibility to discuss and develop terms of research with both funders and implementers. They should scrutinise all grants carefully and refuse those that have unfavourable contractual provisions (eg, those that limit researchers from disseminating potentially critical findings).

Senior leadership should also create a supportive, collegial environment for all research staff facing attempts at censorship, including providing legal support when necessary and, ideally, referral to a cross-institutional or national ombudsperson who can serve as a reference point for particular research areas or disciplines. They should extend support to individuals subcontracted to conduct research on behalf of institutions, who may be in especially vulnerable positions.

In addition, senior leadership should encourage methodological and disciplinary diversity to capture complexity and value the dissemination of both positive and negative research findings. Senior research staff being prepared to disseminate controversial and politically contentious analyses can pave the way for more junior researchers to do the same. Research ethics and integrity issues should be part of research training programmes. Research institutions can also provide researchers with access to mentors external to their research group, particularly for junior staff with soft funding. Unions can play an important role if institutional leadership fails.

\section{ETHICS AND RESEARCH GOVERNANCE COMMITTEES}

Ethics committees play a crucial role in ensuring the independence and integrity of research. Researchers seek approval from ethics committees, usually both at their research institutions and in the countries in which research is undertaken. Such committees have a remit to safeguard ethical conduct of research and protect the rights and welfare of research subjects, and primarily draw on biomedical research paradigms to do so. Although research ethics committees do often consider the safety 
risks posed to individual researchers (injury and incarceration), they do not typically consider concerns about protecting the researchers from interference and threats to their credibility. Therefore, they could play a fuller role in helping researchers navigate related unforeseen ethical dilemmas that arise in the course of research. For example, they can provide guidance on whether to extend protections intended for individual research subjects (eg, to 'do no harm') to organisations. They could also advice researchers on how to balance their ethical obligations to research participants and their obligations to wider society in the face of pressure from vested interests. $^{27}$

Ethics committees should have representation from different research fields, with members who are trained in the epistemological and methodological bases of different disciplines. ${ }^{28}$ In addition, procedures for ensuring the independence of ethics committees are vital to prevent a situation in which members' close ties to senior management, funders, ruling parties, governments or commercial interests lead them to use regulatory frameworks to shut down 'unfavourable' or disruptive research.

University research governance offices, where they exist, can complement ethics committees by protecting the rights and welfare of researchers especially where research challenges powerful agendas. They can offer advice and arbitration assistance to researchers on conflicts of interest arising in relation to external research funding. They can monitor for instances of unethical practice to enable research institutions to push back if powerful external actors manipulate research ethics regulations to constrain the research process, as some British universities have done in the past. ${ }^{29}$ Research institutions should develop clear value statements and commit to implementing them through their ethics and governance protocols.

\section{ACADEMIC JOURNALS AND EDITORS}

The current practice is that academic journals ask or expect authors to declare any conflicts of interest relating to a publication. Journals ought to be challenging of these statements and refrain from publishing what is stated by authors in cases when it is obvious there is a gross conflict. Additional conflict of interest statements should be required from any co-authors that are part of the funding organisation. This can prevent funders from putting pressure on researchers to be included as co-authors of papers emanating from the research and use this role to influence how the results are reported.

Academic journal editors have considerable potential to contribute towards dismantling the 'success cartel' within global health, for example, by publishing negative findings, and encouraging papers that explain the 'hows and whys' of both positive and negative findings. ${ }^{30}$ This includes process evaluations and in-depth political and social analyses of global health policy and practice, especially when these challenge the status quo. Editors of academic journals that publish global health research and evaluations should create procedures to select diverse peer reviewers without a vested interest and support them to rigorously question manuscripts that present uncritical and unexplained success stories. Editors should ensure diversity among peer reviewers and moderate dialogue between authors and peer reviewers where, for example, junior authors can challenge unduly hostile or politically motivated reviews by senior academics. They should ideally invite commentaries and responses from donor agencies, NGOs, civil society members, policy makers and researchers from the countries in which research and evaluations have been commissioned.

\section{CONCLUSION}

The tensions between research ethics and the wider politics of the global health field are increasingly recognised. However, the repercussions of these tensions for individuals and research institutions need careful consideration. While 'rocking the boat' is uncomfortable and may threaten individual career progression and research institutions' external income, biased evidence can harm health programme beneficiaries and public trust in research. There are certainly no simple, fail-safe, technocratic quick fixes to resolving issues of power and politics, but the ideas proposed here should at least create better relationships between the institutions involved in commissioning, undertaking and publishing research, and feed into more sophisticated and thoughtful mechanisms of accountability, which do not simply re-enforce existing frameworks that favour accountability towards donors. The ideas we propose should be considered within broader discussions on how to address northsouth power imbalances within the research community, and will hopefully catalyse wider action on protecting the independence of public universities and other research institutions globally. We believe this is necessary to enable researchers to hold power to account and advance informed and healthy debate on issues of public interest.

Acknowledgements We would like to thank the following individuals for substantive inputs to this editorial: Salla Atkins, Diego Bassani, Dominique Béhague, Uli Beisel, Antoine de Bengy Puyvallée, Karl Blanchet, Oriane Bodson Till Bruckner, Sarah Dalglish, Tanya Doherty, Lara Gautier, Asha George, Lucy Gilson, Nora Kenworthy, Sarah Hawkes, Kristine Husøy Onarheim, Shelley Lees, Frédéric le Marcis, Mehr Manzoor, James Pfeiffer, Emma Sacks, Rusla Anne Springer, Veena Sriram, Anne-Marie Turcotte-Tremblay, Lauren Wallace and Anthony Zwi. We would also like to thank Svea Closser, Judith Justice and Jeremy Shiffman for their part in the panel at the 2018 Global Symposium on Health Systems Research that sparked this discussion.

Signatories Abejirinde, Ibukun, Independent Researcher and Consultant, Toronto, Canada. Abimbola, Seye, The University of Sydney, Australia. Adebiyi, Babatope, University of the Western Cape, South Africa. Affun-Adegbulu, Clara, Institute of Tropical Medicine/ University of Antwerp, Belgium. Ahlgren, Jhon Álvarez, Karolinska Institutet, Sweden. Ahmad, Ayesha, St George's University of London/ University College London, United Kingdom. Akello, Grace, Gulu Univerity, Uganda. Al-Awlaqi, Sameh, Independent consultant, Yemen. Aloys, Zongo, Ministere de la santé, Burkina Faso. Amul, Gianna Gayle, University of Geneva, Switzerland/ National University of Singapore, Singapore. Arthur, Joshua, Public Health Unit, Komfo Anokye Teaching Hospital, Ghana. Asaduzzaman, Muhammad, University of Oslo, Norway. Asgedom, Akeza Awealom, University of Bergen, Norway. Assarag, 
Bouchra, National School of Public Health, Morocco. Atchessi, Nicole, Université d'Ottawa, Canada. Atkins, Salla, Tampere University, Finland. Badejo, Okikiolu, Institute of Tropical Medicine/University of Antwerp, Belgium/APIN Public Health Initiatives, Nigeria. Bærøe, Kristine, University of Bergen, Norway. Bailah Molleh, Sustainable Health Systems, Sierra Leone, Balabanova, Dina, London School of Hygiene \& Tropical Medicine, United Kingdom. Bazzano, Alessandra, Tulane University, USA. Béhague, Dominique P., Vanderbilt University, USA/Kings College London, United Kingdom. Beisel, Uli, University of Bayreuth, Germany. Belaid, Loubna, McGill University, Canada. Bernays, Sarah, London School of Hygiene and Tropical Medicine and School of Public Health/ University of Sydney, Australia. Bhuiyan, Shafi, University of Toronto, Canada. Biermann, Olivia, Karolinska Institutet, Sweden. Birungi, Harriet, Population Council, Kenya. Blanchet, Karl, London School of Hygiene and Tropical Medicine, United Kingdom. Blystad, Astrid, University of Bergen, Norway. Bodson, Oriane, Université de Liège, Belgium. Bonnet, Emmanuel, Centre IRD de Ouagadougou, Burkina Faso. Bose, Shibaji, Independant Consultant, Future Health System, Norway. Bozorgmehr, Kayvan, Bielefeld University/ Heidelberg University Hospital, Germany. Brear, Michelle, University of the Free State- Qwaqwa, South Africa. Burgess, Rochelle, University College London, United Kingdom. Byskov, Jens, University of Copenhagen, Denmark/University of Zambia, Zambia. Carillon, Séverine, Ceped, Université Paris Descartes/ L'Institut de recherche pour le développement (IRD), France. Cavallaro, Francesca L., L'Institut de recherche pour le développement (IRD), France. Chabeda, Sophie, KEMRI Wellcome Trust Research Programme, Kenya. Chandler, Clare, London School of Hygiene \& Tropical Medicine, United Kingdom. Chapman, Rachel University of Washington, Seattle, USA. Chikuse, Francis F., Pathcare, Namibia. Chinwe, Juliana Iwu, Stellenbosch University, South Africa. Cislaghi, Beniamino, London School of Hygiene and Tropical Medicine, United Kingdom. Closser, Svea, Johns Hopkins Bloomberg School of Public Health, USA. Colvin, Christopher J., University of Cape Town, South Africa. Cresswell, Jenny, London School of Hygiene \& Tropical Medicine, United Kingdom. da Cunha Saddi, Fabiana, Federal University of Goias, Brazil. Daire, Judith, Curtin University, Perth, Australia. Dalglish, Sarah, Johns Hopkins School of Public Health, USA. de Brouwere, Vincent, Institute of Tropical Medicine, Belgium. de Sardan, Jean-Pierre Olivier, Laboratoire d'études et de recherches sur les dynamiques sociales et le développement local (LASDEL), Niger. Delvaux, Thérèse, Institute of Tropical Medicine, Belgium. Desgrées du Loû, Annabel, L'Institut de recherche pour le développement (IRD), France. Diallo, Brahima A., MRC Unit The Gambia at London School of Hygiene \& Tropical Medicine, The Gambia. Diarra, Aïssa, Laboratoire d'études et recherches sur les dynamiques sociales et le développement local, Niger. Dixon, Justin, London School of Hygiene and Tropical Medicine, United Kingdom. Doherty, Tanya, South African Medical Research Council, South Africa. Dumont, Alexandre, L'Institut de recherche pour le développement (IRD), France. Eboreime, Ejemai, National Primary Health Care Development Agency, Nigeria. Engelbrecht, Beth, Provincial Department of Health, Western Cape Government, South Africa. Erikson, Susan, Simon Fraser University, Canada. Faye, Adama, Université de Dakar, Senegal. Filippi, Véronique, London School of Hygiene \& Tropical Medicine, United Kingdom. Fischer, Sara, Georgetown University, USA. Fournet, Florence, L'Institut de recherche pour le développement (IRD), Côte d'Ivoire. Fox, Ashley M., Assistant Professor, Rockefeller College of Public Affairs and Policy, University at Abany, USA. Francis, Joel Msafiri, University of the Witwatersrand, South Africa. Gautier, Lara, Université de Montréal, Canada. George, Asha, University of the Western Cape, South Africa. Gilson, Lucy, University of Cape Town, South Africa/London School of Hygiene and Tropical Medicine, United Kingdom. Gimbel, Sarah, University of Washington, USA. Glenn, Jeff, Brigham Young University, USA. Gopinathan, Unni, University of Oslo, Norway. Gordeev, Vladimir S., Queen Mary University of London/ London School of Hygiene \& Tropical Medicine, United Kingdom. Gradmann, Christoph, University of Oslo, Norway. Graham, Janice E. Dalhousie University, Canada. Gram, Lu, University College London, United Kingdom. Greco, Giulia, London School of Hygiene \& Tropical Medicine, United Kingdom. Grepin, Karen, Wilfrid Laurier University, Canada. Guichard, Anne, Université Laval, Canada. Gupta, Pragya Tiwari, Ethiopian Civil Service University, Ethiopia. Guzman, Viveka, Trinity College Dublin, Ireland. Haaland, Marte E. S., University of Bergen, Norway. Häggblom, Anna, Global Health Advisors, Norway. Hagopian, Amy, University of Washington, USA. Hammarberg, Karin, Monash University, Australia. Handschumacher, Pascal, Université de Strasbourg, France. Hann, Katrina, Sustainable Health Systems, Sierra Leone. Hasselberg, Marie, Karolinska Institutet, Sweden. Hawkes, Sarah, University College London, United Kingdom. Howard, Natasha, London School of Hygiene \& Tropical Medicine, United Kingdom. Hurtig, Anna-Karin, Umeå University, Sweden. Hussain, Sameera, University of Ottawa/ Canadian Society for International Health, Canada. Hutchinson, Eleanor, London School of Hygiene and Tropical Medicine, United Kingdom. Idoteyin, Ezirim, National Agency for the Control of AIDS, Nigeria. Infanti, Jennifer J., Norwegian University of
Science and Technology, Norway. Irwin, Rachel, Lund University, Sweden. Islam, Shariful, Deakin University, Australia. Joarder, Taufique, FHI 360- Bangladesh Office, Bangladesh. John, Preethi, Chitkara University, India. Johnson, Ermel, West African Health Organisation, Burkina Faso. Johri, Mira, Université de Montréal, Canada. Justice, Judith, University of California San Francisco, USA. Kaboré, Charles. Centre National de la Recherche Scientifique et Technologique, Burkina Faso. Kadio, Kadidiatou, Centre National de la Recherche Scientifique et Technologique, Burkina Faso. Kamwa, Matthieu, HDM Consulting/Global Health/York University, Canada. Kelly, Ann H., King's College London, United Kingdom. Kenworthy, Nora, University of Washington Bothell, USA. Kittelsen, Sonja, University of Oslo, Norway. Kloster, Maren Olene, University of Oslo, Norway. Kocsis, Emily, Canadian Coalition for Global Health Research, Canada. Koon, Adam, Johns Hopkins University, USA. Kumar, Pratap, Strathmore University Business School, Kenya. Lal, Arush, London School of Hygiene \& Tropical Medicine/London School of Economics, United Kingdom. Lange, Isabelle, London School of Hygiene and Tropical Medicine, United Kingdom. Lanthorn, Heather, IDinsight, USA. Le Marcis, Frederic, ENS de Lyon, France. Lees, Shelley, London School of Hygiene and Tropical Medicine, United Kingdom. Lexchin, Joel, York University, Canada. Lie, Ann Louise, University of Oslo, Norway. Limenih, Gojjam, University of Alberta/University of British Columbia, Canada. Litwin-Davies, Isabel, London School of Hygiene \& Tropical Medicine, United Kingdom. Lodda, Charles Clarke, University of Bath, United Kingdom. Lönnroth, Knut, Karolinska Institutet, Sweden. Manton, John, London School of Hygiene and Tropical Medicine, United Kingdom. Manzi, Anatole, Partners in Health, USA/University of Global Health Equity, Rwanda. Manzoor, Mehr, Tulane University, USA. Marchal, Bruno, Institute of Tropical Medicine, Belgium. Marten, Robert, London School of Hygiene and Tropical Medicine, United Kingdom. Matsui, Mitsuaki, Nagasaki University School of Tropical Medicine and Global Health, Japan. Mbewe, Allan, University of Zambia, Zambia. Mc Sween-Cadieux, Esther, Université de Montréal, Canada. McGoey, Linsey, University of Essex, United Kingdom. McNeill, Desmond, University of Oslo, Norway. Mendenhall, Emily, Georgetown University, USA. Méndez, Claudio A., Universidad Austral de Chile, Chile. Mirzoev, Tolib, University of Leeds, United Kingdom. Mohammed, Shafiu, Ahmadu Bello University, Nigeria. Moland, Karen Marie, University of Bergen, Norway. Molyneux, Sassy KEMRI Wellcome Trust Research Programme, Kenya/ University of Oxford, United Kingdom. Mumtaz, Zubia, University of Alberta, Canada. Murray, Susan Fairley, King's College London, United Kingdom. Nambiar, Devaki, George Institute for Global Health, India. Nelson, Erica, London School of Hygiene and Tropical Medicine, United Kingdom. Nieto-Sanchez, Claudia, Institute of Tropical Medicine, Belgium. Norheim, Ole Frithjof, University of Bergen, Norway. Nouvet, Elysée, University of Western Ontario, Canada. Obare, Francis, Population Council, Kenya. Okungu, Vincent, University of Nairobi, Kenya. Onarheim, Kristine Husøy, University College London, United Kingdom. Østebø, Marit Tolo, University of Florida, USA.Ouattara, Fatoumata, L'Institut de recherche pour le développement (IRD), Togo/France. Ozawa, Sachiko, University of North Carolina at Chapel Hill, USA. Pai, Madhukar, McGill University, Canada. Paina, Ligia, Johns Hopkins University School of Public Health, USA. Palmer, Jennifer, London School of Hygiene \& Tropical Medicine, United Kingdom. Parashar, Rakesh, Tata Institute of Social Sciences, India. Parker, Melissa, London School of Hygiene \& Tropical Medicine, United Kingdom. Paul, Elisabeth, Université libre de Bruxelles, Belgium. Peeters, Koen, Institute of Tropical Medicine, Belgium. Pennetier, Cédric, L'institut de recherche pour le développement (IRD), Côte d'Ivoire. Penn-Kekana, Loveday, London School of Hygiene \& Tropical Medicine, United Kingdom. Peters, David, Johns Hopkins University Bloomberg School of Public Health, USA. Pfeiffer, James, University of Washington, Seattle/Health Alliance International, USA. Pot, Hanneke, University of Oslo, Norway. Prashanth, N.S., Institute of Public Health, Bangalore, India. Preston, Robyn, CQ University, Australia. Puyvallee, Antoine de Bengy, University of Oslo, Norway. Rahmalia, Annisa, Radboud University Medical Center, Netherlands. ReidHenry, Simon, Queen Mary, University of London, United Kingdom. Ridde, Valéry, L'Université Paris Descartes/ L'Institut de Recherche pour le Développement, France. Roalkvam, Sidsel, University of Oslo, Norway. Rodríguez, Daniela C. Johns Hopkins School of Public Health, USA. Ronse, Maya, Institute of Tropical Medicine, Belgium. Sacks, Emma, Johns Hopkins School of Public Health, USA. Samb, Oumar Mallé, Université du Québec, Canada. Sanders, David, University of the Western Cape, South Africa. Sarkar, Nandini, D.P. Institute of Tropical Medicine, Belgium. Sarriot, Eric, Save the Children USA, USA. Scheel, Inger Brummenæs, Norwegian Institute of Public Health, Norway. Schwarz, Thomas, Medicus Mundi International Network, Switzerland. Scott, Kerry, Johns Hopkins Bloomberg School of Public Health, USA. Seeley, Janet, London School of Hygiene \& Tropical Medicine, United Kingdom. Seward, Nadine, Kings College London, United Kingdom. Shannon, Geordan, University College London, United Kingdom. Shearer, Jessica, Health Systems Innovation and Delivery Program, PATH, USA. Shelley, Katharine Health Systems Innovation and Delivery Program, PATH, USA. Sherr, Kenneth, University of 
Washington/Health Alliance International, USA. Shiffman, Jeremey, Johns Hopkins University, USA. Simard, Frédéric, L'institut de recherche pour le développement (IRD), France. Singh, Neha S., London School of Hygiene and Tropical Medicine, United Kingdom. Soors, Werner, Institute of Tropical Medicine, Belgium. Springer, Rusla Anne, University of Saskatchewan, Canada. Storeng, Katerini T., University of Oslo, Norway/London School of Hygiene \& Tropical Medicine, United Kingdom. Strong, Adrienne, University of Florida, USA. Sundby, Johanne, University of Oslo, Norway. Taylor, Stephen, Queen Mary University of London, United Kingdom. Tetui, Moses, Makerere University School of Public Health, Uganda. Topp, Stephanie M., James Cook University, Australia. Tsofa, Benjamin, KEMRI Wellcome Trust Research Programme, Kenya. Turcotte-Tremblay, Anne-Marie, Université de Montréal, Canada. Undie, Chi-Chi, Population Council, Kenya. Van Belle, Sara, Institute of Tropical Medicine, Belgium. Van Heteren, Godelieve, Independent Consultant, The Netherlands. van Rensburg, André Janse, University of KwaZulu-Natal, South Africa. Veena Sriram, University of Chicago, USA. Venkatapuram, Sridhar, King's College London, United Kingdom. Wagenaar, Bradley H., University of Washington, USA. Wallace, Lauren, McMaster University, Canada. Walugembe, David R., University of Western Ontario, Canada. Wariri, Oghenebrume. MRC Unit the Gambia at the London School of Hygiene and Tropical Medicine, The Gambia. Whiteside, Alan OBE, University of KwaZulu-Natal, South Africa/Wilfrid Laurier University and the Balsillie School of International Affairs, Canada. Yakob, Bereket, Harvard T.H. Chan School of Public Health, Ethiopia. Zakayo, Scholastica, KEMRI Wellcome Trust Research Programme, Kenya. Zitti, Tony Université Paris Descartes, France. Zwi, Anthony, University of New South Wales, Australia.

Funding The authors have not declared a specific grant for this research from any funding agency in the public, commercial or not-for-profit sectors.

Competing interests Some of the authors receive research funding from donor agencies to evaluate their programmes.

Patient consent for publication Not required.

Provenance and peer review Commissioned; internally peer reviewed.

Data availability statement № additional data are available.

Open access This is an open access article distributed in accordance with the Creative Commons Attribution Non Commercial (CC BY-NC 4.0) license, which permits others to distribute, remix, adapt, build upon this work non-commercially, and license their derivative works on different terms, provided the original work is properly cited, appropriate credit is given, any changes made indicated, and the use is non-commercial. See: http://creativecommons.org/licenses/by-nc/4.0/.

\section{REFERENCES}

1. Storeng KT, Palmer J. When ethics and politics collide in donorfunded global health research. The Lancet 2019:pii: S01406736(19)30429-5.10.1016/S0140-6736(19)30429-5. [Epub ahead of print].

2. Fassin D. The obscure object of global health. In: Inhorn MC, Wentzell EA, eds. Medical anthropology at the intersections. Durhan and London: Duke University Press, 2010: 95-115.

3. Shiffman J. Global health as a field of power relations: a response to recent commentaries. Int J Health Policy Manag 2015;4:497-9.

4. Doherty T, Lewin S, Kinney M, et al. Addressing the tensions and complexities involved in commissioning and undertaking implementation research in low- and middle-income countries. BMJ Glob Health 2018;3:e000741.

5. Gautier L, Ridde V. Did the learning agenda of the world Bankadministrated health results innovation trust fund shape politicised evidence on Performance-based financing? A documentary analysis. Sociedade e Cultura 2018;21:27-53.
6. Blank MB, Jemmott JB. The CDC clearance process: an obstacle to progress in public health. Am J Public Health 2015;105:614-5.

7. Hagopian A, Stover B, Barnhart S. CDC clearance process constitutes an obstacle to progress in public health. Am J Public Health 2015;105:e1.

8. Viergever RF, Hendriks TCC. The 10 largest public and philanthropic funders of health research in the world: what they fund and how they distribute their funds. Health Res Policy Syst 2016;14.

9. Rajkotia Y. Beware of the success cartel: a plea for rational progress in global health. BMJ Glob Health 2018;3:e001197.

10. Gaitonde R, Oxman AD, Okebukola PO, et al. Interventions to reduce corruption in the health sector. Cochrane Database Syst Rev 2016;135.

11. Mumtaz Z, Ferguson A, Bhatti A, et al. Learning from failure? politica expediency, evidence, and inaction in global maternal health. Soc Sci Med 2017. doi:10.1016/j.socscimed.2017.05.032

12. Mumtaz Z, Ellison GTH, Ferguson A, et al. A call for transparency in the evaluation of global maternal health projects. Lancet 2016;388.

13. Sandefur J, Glassman A. The political economy of BAD data: evidence from African survey and administrative statistics. J Dev Stud 2015;51:116-32.

14. Jerven M. Poor numbers: how we are misled by African development statistics and what to do about it. Cornell University Press, 2013.

15. Turcotte-Tremblay A-M, De Allegri M, Gali-Gali IA, et al. The unintended consequences of combining equity measures with Performance-based financing in Burkina Faso. Int $J$ Equity Health 2018;17.

16. McCoy D, Jensen N, Kranzer K, et al. Methodological and policy limitations of quantifying the saving of lives: a case study of the global fund's approach. PLoS Med 2013;10:e1001522.

17. The Independent Commission for Aid Impact. Assessing DFID's results in improving Maternal Health. London The Independent Commission for Aid Impact 2018.

18. Heldt EC. Lost in internal evaluation? Accountability and insulation at the world bank. Contemporary Politics 2018;24:568-87.

19. Friebel R, Silverman R, Glassman A, et al. On results reporting and evidentiary standards: spotlight on the global fund. Lancet 2019;393:2006-8.

20. DFID. Department for international development (DFID) standard terms and conditions - service contracts 2019.

21. Lexchin J, Bero LA, Djulbegovic B, et al. Pharmaceutical industry sponsorship and research outcome and quality: systematic review. BMJ 2003;326:1167-70.

22. Kelly RE, Cohen LJ, Semple RJ, et al. Relationship between drug company funding and outcomes of clinical psychiatric research. Psychol Med 2006;36:1647-56.

23. Bero L, Oostvogel F, Bacchetti P, et al. Factors associated with findings of published trials of drug-drug comparisons: why some statins appear more efficacious than others. PLoS Med 2007;4:e184

24. Goldacre B. Is the conflict of interest unacceptable when drug companies conduct trials on their own drugs? Yes. BMJ 2009;339:b4949.

25. Lawton V. Is the conflict of interest unacceptable when drug companies conduct trials on their own drugs? No. BMJ 2009;339:b4953.

26. Ioannidis JP. Clinical trials: what a waste. British Medical Journal Publishing Group 2014.

27. Economic and Social Research Council. ESRC framework for research ethics 2015.

28. Molyneux S, Tsofa B, Barasa E, et al. Research involving health providers and managers: ethical issues faced by researchers conducting diverse health policy and systems research in Kenya. Dev World Bioeth 2016;16:168-77.

29. Reisz M. Unwanted side-effects. Times Higher Education 2013.

30. Daniels K, Loewenson R, George A, et al. Fair publication of qualitative research in health systems: a call by health policy and systems researchers. Int J Equity Health 2016;15. 